\title{
Natural Vibration of a Beam with a Breathing Oblique Crack
}

\author{
Yijiang Ma and Guoping Chen \\ State Key Laboratory of Mechanics and Control for Mechanical Structures, Nanjing University of Aeronautics and Astronautics, \\ Nanjing 210016, China \\ Correspondence should be addressed to Yijiang Ma; yima@nuaa.edu.cn
}

Received 10 November 2016; Revised 13 January 2017; Accepted 29 January 2017; Published 22 February 2017

Academic Editor: Ivo Caliò

Copyright (C) 2017 Yijiang Ma and Guoping Chen. This is an open access article distributed under the Creative Commons Attribution License, which permits unrestricted use, distribution, and reproduction in any medium, provided the original work is properly cited.

\begin{abstract}
An analytical method is proposed to calculate the natural frequency of a cantilever beam with a breathing oblique crack. A double-linear-springs-model is developed in the modal analysis process to describe the breathing oblique crack, and the breathing behaviour of the oblique crack is objectively simulated. The finite element method (FEM) analysis software ABAQUS is used to calculate the geometric correction factors when the cracked plate is subjected to a pure bending moment at different oblique crack angles and relative depths. The Galerkin method is applied to simplify the cracked beam to a single degree of freedom system, allowing the natural frequency of the beam with the breathing oblique crack to be calculated. Compared with the natural frequencies of the breathing oblique cracked beam obtained using the ABAQUS FEM method, the proposed analytical method exhibits a high computational accuracy, with a maximum error of only $4.65 \%$.
\end{abstract}

\section{Introduction}

Beams are widely used structures and that inevitably experience damage due to vibrations. Structural damage typically occurs in the form of cracks, which have been the focus of numerous studies. Cracks can be divided into open cracks and breathing cracks based on the different vibrational characteristics. Vibration analysis typically assumes that cracks remain open. Papadopoulos and Dimarogonas [1] used a $2 \times 2$ local flexibility matrix to model a transverse open crack using a coupled longitudinal and bending vibration analysis of a cracked shaft. Chondros et al. [2] developed a continuous cracked beam vibration theory to analyse the lateral vibrations of cracked Euler-Bernoulli beams with single-edge or double-edges open cracks. However, cracks exhibit a closed state in a compressive nominal stress field. Therefore, vibration analysis of the cracked structure does not properly evaluate the actual situation by assuming that the crack is open.

Compared to open cracks, breathing cracks can describe the vibrational cracked structure more objectively. Chondros et al. [3] assumed a beam with a breathing transverse crack to be a piecewise linear system with two states, either fully open or fully closed. A continuous cracked beam vibration theory was used to predict transverse vibration changes of a simply supported beam with a breathing crack. Abraham and Brandon [4] assumed that the transverse crack separated a cantilever beam into two segments and used time varying connection matrices to connect the two segments; then the breathing crack was analysed using linear and nonlinear modelling methodologies. Cheng et al. [5] examined the dynamic response of a transverse breathing crack in a single degree of freedom system and analysed the dynamic vibrating behaviour of a breathing cracked beam. Wu [6] developed an iteration numerical model to investigate the forced vibration characteristics of a cantilever beam with a transverse breathing crack, and the model proposed could also be applied to predict the fatigue life of the cracked beam at the crack position. In summary, several breathing crack models have been proposed to analyse natural vibrations in the transverse cracked beams. The natural frequency of a cracked beam can be obtained via the application of different boundary conditions, but the influence of the oblique crack angle on the natural frequency of the beam is often neglected.

Several methods have been proposed to calculate the stress intensity factors $K_{\mathrm{I}}$ and $K_{\mathrm{II}}$ for an oblique crack at 
the edge of a half-plane [7-12]. Beghini and Santus [13] developed a Weight Function (WF) to calculate the stress intensity factors at the tip of a pressurization surface crack in a plane. Beghini et al. [14] also developed an efficient and accurate analytical WF to calculate the stress intensity factors of inclined cracks at sharp V-notches. Leung and Su [15] used a fractal two-level finite element method (F2LFEM) to determine the stress intensity factors of a central slant crack in a square sheet subjected to biaxial tensile stress. Jweeg et al. [16] assumed an oblique crack in plate as a horizontal and vertical crack and divided the cracked plate into four parts. The four parts were then analysed and the natural frequency was obtained using an orthogonal method. Based on the assumption that the crack on the beam was open, Al-Waily [17] used the Fourier series method to solve the equivalent stiffness of an oblique cracked beam, and the natural frequencies were easily obtained from the general motion equation solution of the obliquely cracked beam; then the natural frequencies obtained were compared to the results using the ANSYS method, and the results exhibited significant agreement, with a maximum error of $1.8 \%$. Although these studies above proposed several methods for analysing the natural vibrations of structures with oblique cracks, they neglected the influence of the crack closure effect.

This paper proposes an analytical method for calculating the natural frequency of a cantilever beam with a breathing oblique crack. A double-linear-springs-model is used to simulate the breathing behaviour of the oblique crack, and the stiffness variation of the cantilever beam can be obtained by calculating the additional flexibility caused by the oblique crack. When the oblique crack has different angles and relative depths, the geometric correction factors are calculated for a unilateral oblique cracked beam subjected to a pure bending moment, and the finite element method (FEM) analysis software ABAQUS is used to calculate these factors. Geometric correction factors of different relative depths but equal angles will be fitted to a function curve using MATLAB software. The vibration of the cracked beam is simplified to a single degree of freedom system using the Galerkin method, which allows the natural frequency of the breathing oblique cracked beam to be calculated. The analytical method proposed in this paper is validated by comparing the analytical method results to the results obtained using the ABAQUS FEM approach. Then the influences of the angle, relative depth, and position of the breathing oblique crack on the natural frequency of the cracked beam are analysed.

\section{Breathing Oblique Cracked Beam Model}

Figure 1 illustrates a cantilever beam with an oblique crack, where $L$ is the length of the beam, $h$ is the height of the beam, $b$ is the thickness of the beam, $a$ is the depth of the oblique crack, $\theta$ is the inclination angle of the oblique crack, and $x_{a}$ is the distance between the crack position and the fixed end. It is assumed that the cantilever beam is homogeneous and isotropic.

Cracks do not always remain open during the vibration of the cracked beam, so the crack closure effect should be considered. Compared with the open crack, the breathing crack

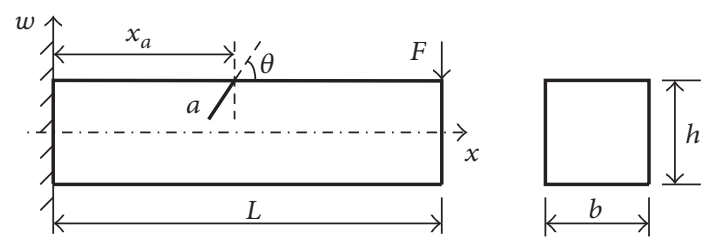

Figure 1: Geometric model of a cantilever beam with an oblique crack.

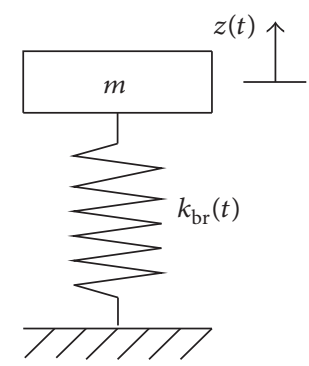

FIGURE 2: Vibration model of a cantilever beam with a breathing oblique crack.

can better describe the vibrational behaviour of the cracked structure. This paper proposes a new breathing crack model that accounts for the crack closure effect. A double-linearsprings-model is used to simulate the breathing behaviour of the oblique crack. A simplified vibration model of a cantilever beam with a breathing oblique crack is shown in Figure 2, and this is a single degree of freedom system, which can solve just one order vibration mode of the beam. Engineering practice shows that the first-order mode has the biggest influence on the vibration fatigue of the beam structure, so the first-order mode of the cracked cantilever beam is mainly studied.

In the process of transverse vibration of the breathing cracked cantilever beam, the crack is always in the alternating state of opening and closing. When the crack is in the state of complete closure, the cracked beam can be replaced by an intact beam, and the stiffness of the cracked beam is the biggest; when the crack is in the state of complete opening, the crack can be replaced by the open mode crack, and the stiffness of the cracked beam is the least.

So, the stiffness of the breathing cracked beam is a combination of the stiffness of the open cracked beam and the stiffness of the closed cracked beam, which is time variant. Assume that the passage from closed to open crack and vice versa occurs in a smooth way, and there is no abrupt change in the bending stiffness of the cracked beam during the vibration [5]:

$$
k_{\mathrm{br}}(t)=k_{o}+\frac{k_{c}-k_{o}}{2}(1+\cos \omega t)
$$

where $k_{\mathrm{br}}(t)$ is the stiffness of the breathing cracked beam, $k_{c}$ is the stiffness of the closed cracked beam, $k_{o}$ is the stiffness of the open cracked beam, and $\omega$ is the frequency of exterior excitation.

When $\omega t=2 n \pi(n=1,2,3, \ldots)$, the crack is in the fully closed state and the cracked beam is equivalent to the beam 
without a crack. Thus, the stiffness of the closed cracked beam can be replaced by the stiffness of the beam without a crack, where $k_{\mathrm{br}}=k_{c}$. When $\omega t=(2 n-1) \pi(n=1,2,3, \ldots)$, the crack is in the fully open state, where $k_{\mathrm{br}}=k_{o}$. The stiffness of the breathing cracked beam can be obtained via the solution of the stiffness of the closed cracked beam and the open cracked beam.

In the vibrational environment, the existence of the crack will reduce the bending stiffness of the cantilever beam, and the flexibility of the cantilever beam will increase. The increased flexibility of the cracked beam caused by the oblique crack is called the local flexibility. According to the principles of fracture mechanics, the local flexibility caused by the oblique crack $S_{a}$ can be obtained by the lateral excitation as follows [18]:

$$
S_{a}=b \frac{\partial^{2}}{\partial F^{2}} \int_{0}^{a} J d a^{*},
$$

where $a$ is the depth of the crack; $b$ is the width of the beam; $F$ is the external transverse force acting at the free end of the cantilever beam; $J$ is the strain energy density, which is given by

$$
J=\frac{1-v^{2}}{E}\left(K_{\mathrm{I}}^{2}+K_{\mathrm{II}}^{2}\right),
$$

where $E$ is the elastic modulus of the material, $v$ is the Poisson's ratio, and $K_{\mathrm{I}}$ and $K_{\mathrm{II}}$ are the stress intensity factors at the tip of the oblique crack.

As shown in Figure 1, the oblique crack belongs to the I-II mixed-mode crack, and the stress intensity factor has two components: $K_{\mathrm{I}}$ and $K_{\mathrm{II}}$. For the plate with an oblique crack subjected to only a pure bending moment, the stress intensity factors $K_{\mathrm{I}}$ and $K_{\mathrm{II}}$ can be obtained from [19]:

$$
\begin{gathered}
K_{\mathrm{I}}=\sigma_{b} \sqrt{\pi a} F_{\mathrm{I} \theta}\left(\frac{a}{h}\right) \\
K_{\mathrm{II}}=\sigma_{b} \sqrt{\pi a} F_{\mathrm{II} \theta}\left(\frac{a}{h}\right),
\end{gathered}
$$

where $\sigma_{b}=6 \mathrm{M} /\left(b h^{2}\right)$ is the bending stress; the bending moment at the crack tip on the crack surface is $M=F\left(L-x_{a}+\right.$ $a \cos \theta) ; F_{\mathrm{I} \theta}(a / h)$ and $F_{\mathrm{II} \theta}(a / h)$ are the geometrical correction factors of the plate with an unilateral oblique crack subjected to the pure bending moment; and [19] provides the curves corresponding to the geometrical correction factors $F_{\mathrm{I} \theta}(a / h)$ of the three angles $\left(\theta=45^{\circ}, 67.5^{\circ}\right.$, and $\left.90^{\circ}\right)$ and $F_{\mathrm{II} \theta}(a / h)$ of two angles $\left(\theta=45^{\circ}, 67.5^{\circ}\right)$. The finite element method will be applied to obtain geometrical correction factor curves from three additional angles $\left(\theta=30^{\circ}, 60^{\circ}, 75^{\circ}\right)$, and these 12 curves are then fitted to 12 dimensionless functions.

The flexibility $S_{o}$ of the cantilever beam with an open oblique crack can be obtained as follows:

$$
S_{o}=S_{c}+S_{a}=\frac{1}{k_{c}}+\frac{1}{k_{a}}=\frac{k_{c}+k_{a}}{k_{c} k_{a}},
$$

where $S_{c}$ is the flexibility of the cantilever beam without cracks; $k_{c}$ is the bending stiffness of the cantilever beam without cracks; $k_{a}$ is the bending stiffness caused by the local flexibility.

Neglecting the shear effect caused by the transverse force, the bending stiffness of the beam with an open oblique crack can be obtained from the following equation:

$$
k_{o}=\frac{1}{S_{o}}=\frac{k_{a} k_{c}}{k_{a}+k_{c}} .
$$

\section{Vibration Analysis}

The bending free vibration differential equation for a uniform and homogeneous straight beam is given by

$$
E I \frac{\partial^{4} w}{\partial x^{4}}+\rho A \frac{\partial^{2} w}{\partial t^{2}}=0
$$

where $I$ is the moment of inertia of the cross-section, $A$ is the area of the cross-section, and $\rho$ is the density of the material.

It is assumed that the transverse natural vibration of the cracked beam is expressed as follows:

$$
w(x, t)=W(x) q(t)
$$

where $W(x)$ is the transverse vibration amplitude function of the neutral axis of the beam cross-section and $q(t)$ is the function describing the law of motion.

According to the boundary conditions of the cantilever beam, the vibration amplitude function can be obtained by

$$
\begin{aligned}
W_{n}(x)= & \left(\cos \lambda_{n} x-\cosh \lambda_{n} x\right) \\
& -v_{n}\left(\sin \lambda_{n} x-\sinh \lambda_{n} x\right),
\end{aligned}
$$

where $n=1,2,3, \ldots ; v_{n}=\left(\cos \lambda_{n} L+\cosh \lambda_{n} L\right) /\left(\sin \lambda_{n} L+\right.$ $\left.\sinh \lambda_{n} L\right) ; \lambda_{n} L$ is the solution of the following equation: $\cos \lambda_{n} L \cosh \lambda_{n} L=-1$; if $n=1$ and $\lambda_{1} L=1.8751$, the first mode shape of the cantilever beam can be easily obtained.

Substituting (8) into (7), a single degree of freedom system can be obtained via the Galerkin method as follows:

$$
\begin{aligned}
m^{*} \frac{\partial^{2} q(t)}{\partial t^{2}}+k^{*} q(t) & =0 \\
m^{*} & =\rho A \int_{0}^{L} W_{n}^{2}(x) d x \\
k^{*} & =E I \int_{0}^{L} W_{n}^{\prime \prime 2}(x) d x,
\end{aligned}
$$

where $m^{*}$ is the generalized mass and $k^{*}$ is the generalized stiffness of the structure without a crack.

When the oblique crack is in the fully closed state $\left(k_{c}=\right.$ $k^{*}$ ), then (10) is the vibration function of the beam for a fully closed crack. If the generalized stiffness of the structure is replaced by the stiffness of the open crack $k_{o}$ and the stiffness of the breathing crack $k_{\mathrm{br}}$, the vibration functions of the open cracked beam and the breathing cracked beam can be obtained. 
According to [20], the natural frequencies of the different type cracked beams can be approximately expressed as

$$
\begin{aligned}
& \omega_{o}=\sqrt{\frac{k_{o}}{m^{*}}} \\
& \omega_{c}=\sqrt{\frac{k_{c}}{m^{*}}},
\end{aligned}
$$

where $\omega_{o}$ is the natural frequency of the open cracked beam and $\omega_{c}$ is the natural frequency of the closed cracked beam.

According to [21], the natural frequency of the breathing cracked beam is not time variant, and the natural frequency of the breathing oblique cracked beam can be obtained as follows:

$$
\omega_{\mathrm{br}}=\frac{2 \omega_{o} \omega_{c}}{\omega_{o}+\omega_{c}}
$$

\section{Finite Element Method}

4.1. Geometric Correction Factor of a Unilateral Oblique Crack. The geometric correction factors $F_{\mathrm{I} \theta}(a / h)$ and $F_{\mathrm{II} \theta}(a / h)$ of a unilateral oblique crack with different angles and relative depths are given by [19]:

$$
\begin{aligned}
& F_{\mathrm{I} \theta}\left(\frac{a}{h}\right)=\frac{K_{\mathrm{I}}}{K_{0}} \\
& F_{\mathrm{II} \theta}\left(\frac{a}{h}\right)=\frac{K_{\mathrm{II}}}{K_{0}},
\end{aligned}
$$

where

$$
K_{0}=\frac{6 M \sqrt{\pi a}}{h^{2}} .
$$

This formula can be applied to any similar rectangular plate with an oblique crack, and the length of the plate is 2.5 times longer than the width, and the distance required between the crack and each side of the plate is at least equal to the width of the plate.

The stress intensity factors $K_{\mathrm{I}}$ and $K_{\mathrm{II}}$ at the crack tip can be used to obtain the geometric correction factors $F_{\mathrm{I} \theta}(a / h)$ and $F_{\mathrm{II} \theta}(a / h)$. In this paper, ABAQUS is used to calculate the stress intensity factors $K_{\mathrm{I}}$ and $K_{\mathrm{II}}$ at the crack tip of the oblique crack by the direct $K_{\mathrm{I}}$ output method.

The position of the unilateral oblique crack and the geometric shape of the rectangular cracked plate are shown in Figure 3 , and both sides are subjected to a bending moment $M$. The width of the plate is given by $h=0.1 \mathrm{~m}$. The depth and angle of the crack are represented by $a$ and $\theta$ respectively. The elastic modulus of the material is $E=210 \mathrm{GPa}$, the Poisson's ratio is $v=0.3$, and the density of the material is $\rho=7860 \mathrm{~kg} / \mathrm{m}^{3}$.

Reference points $A$ and $B$ are defined at the midpoints of the left and right sides of the plate, respectively, and the coupling constraints are established between the left and right
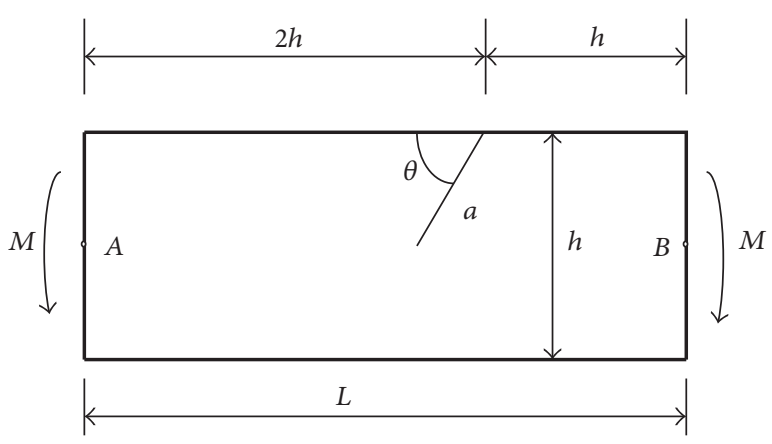

FIGURE 3: Geometric shape of a rectangular cracked plate under a bending moment.

sides of the plate and the reference points, respectively. The bending moments are loaded on the reference points, and the bending moments are loaded on the left and right sides of the plate finally.

ABAQUS is used to conduct the two-dimensional finite element analysis of the cracked plate, with the angles of oblique crack $\theta=30^{\circ}, 45^{\circ}, 60^{\circ}, 67.5^{\circ}, 75^{\circ}$, and $90^{\circ}$ and the relative depths of oblique crack $a / h=$ $0.1,0.2,0.3,0.35,0.4,0.45,0.5,0.55$, which is used to calculate the stress intensity factors $K_{\mathrm{I}}$ and $K_{\mathrm{II}}$ at the crack tip. Because the crack is an ideal sharp crack, the triangular elements CPS6 are used to eliminate the influence the stress field singularity around the crack tip, and the quadrilateral elements CPS8 are used in other regions. The meshes near the crack tip must be refined, and the minimum distance between the nodes near the crack tip is less than $0.02 a$, which meets the requirements of the calculation and improves the accuracy. In the Interaction Module of ABAQUS, the stress singularity at the oblique crack is set up. In the Step Module, the output of the stress intensity factors at the crack tip is created. After creating the load, the calculation is carried out, and the stress intensity factors $K_{\mathrm{I}}$ and $K_{\mathrm{II}}$ can be easily obtained. Then the geometric correction factors $F_{\mathrm{I} \theta}(a / h)$ and $F_{\mathrm{II} \theta}(a / h)$ can be obtained by substituting the stress intensity factors into (15).

When the relative depths and angles of the oblique crack are $a / h \in[0.3,0.55]$ and $\theta=45^{\circ}, 67.5^{\circ}$, and $90^{\circ}$, the three geometric correction factors curves of $F_{\mathrm{I} \theta}(a / h)$ are listed in [19]; when the relative depths and angles of the oblique crack are $a / h \in[0.3,0.55]$ and $\theta=45^{\circ}$ and $67.5^{\circ}$, the two geometric correction factors curves of $F_{\mathrm{II} \theta}(a / h)$ are also listed in [19]. Geometric correction factors are also calculated for the oblique crack with a relative depth of $a / h=0.1,0.2$. These factors improve the accuracy of the curves that were fit using MATLAB. Figure 4 compares the geometric correction factors $F_{\mathrm{I} \theta}(a / h)$ and $F_{\mathrm{I} \theta}(a / h)$ obtained from ABAQUS and the results from [19] for different angles of the oblique crack.

As shown in Figure 4, the values obtained by ABAQUS are similar to the values from [19], suggesting that the twodimensional mesh model established by ABAQUS possesses a high accuracy and can be effectively used to calculate the geometrical correction factors $F_{\mathrm{I} \theta}(a / h)$ and $F_{\mathrm{II} \theta}(a / h)$. 


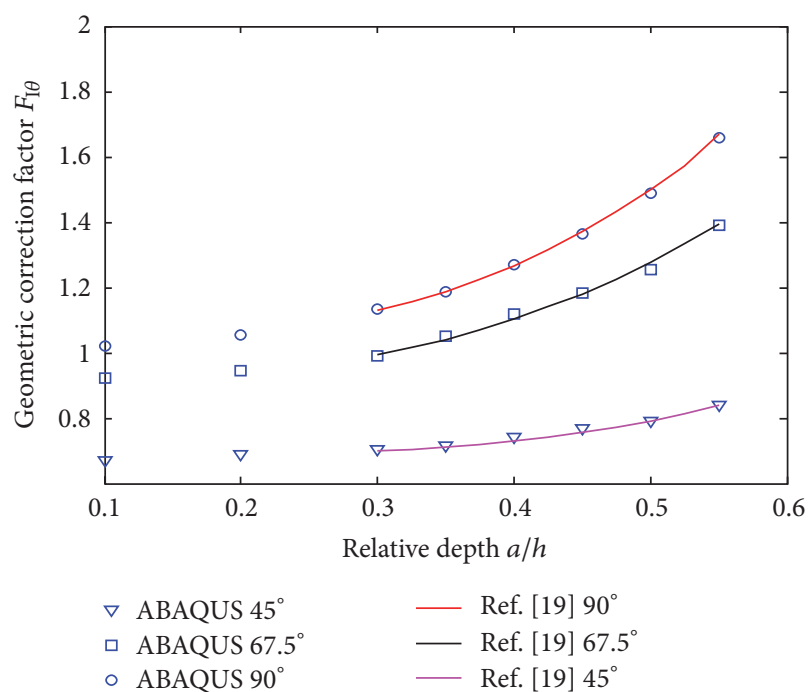

(a) Geometric correction factors $F_{\mathrm{I} \theta}(a / h)$

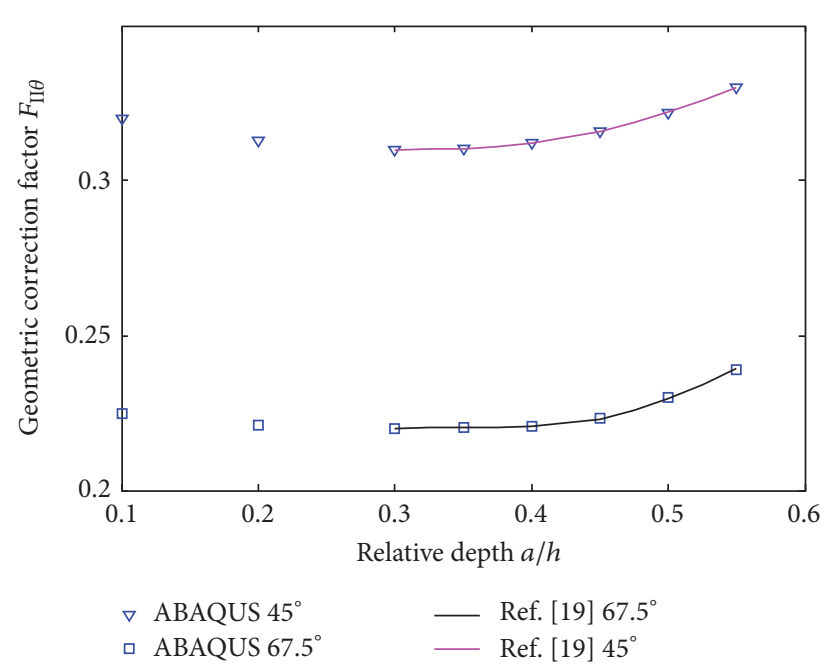

(b) Geometric correction factors $F_{\mathrm{II} \theta}(a / h)$

FIgURE 4: Geometric correction factors $F_{\mathrm{I} \theta}(a / h)$ and $F_{\mathrm{II} \theta}(a / h)$.

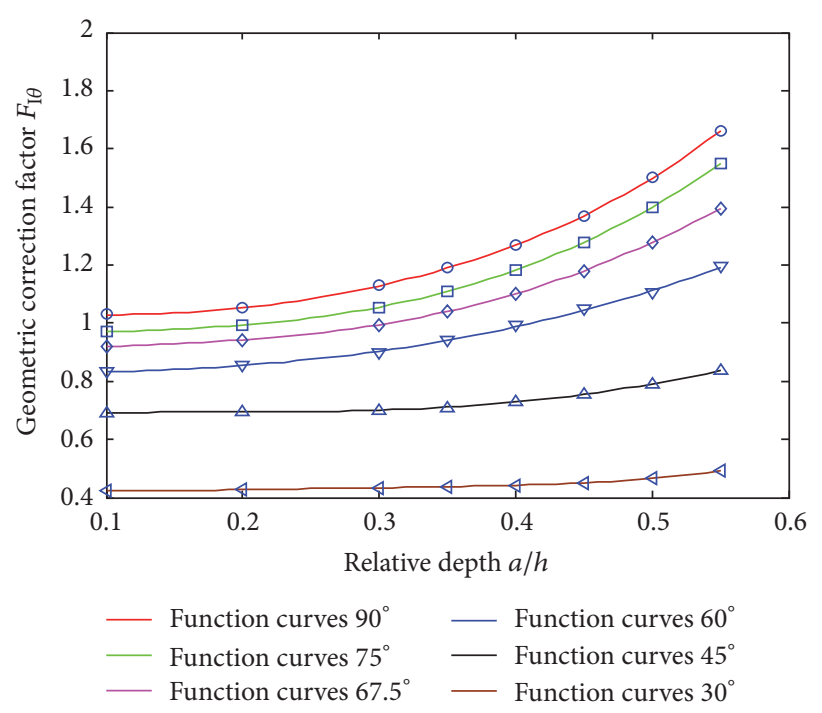

(a) Six function curves of $F_{\mathrm{I} \theta}(a / h)$ fitted

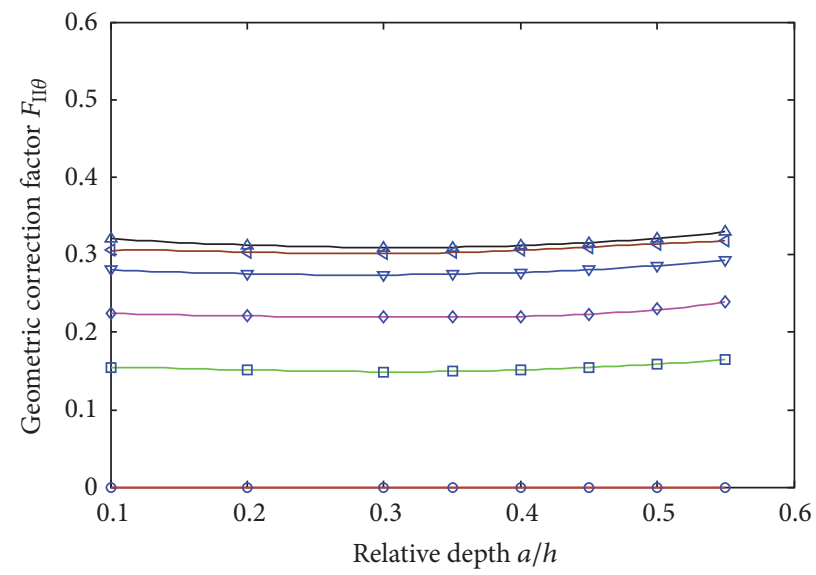

$\begin{array}{ll}\text { Function curves } 90^{\circ} & \text { Function curves } 60^{\circ} \\ \text { Function curves } 75^{\circ} & - \text { Function curves } 45^{\circ} \\ \text { Function curves } 67.5^{\circ} & - \text { Function curves } 30^{\circ}\end{array}$

(b) Six function curves of $F_{\mathrm{II} \theta}(a / h)$ fitted

FIGURE 5: 12 function curves fitted from 12 geometric correction factor groups.

12 groups of geometric correction factors $F_{\mathrm{I} \theta}(a / h)$ and $F_{\mathrm{II} \theta}(a / h)$ are obtained using ABAQUS for oblique crack angles of $\theta=30^{\circ}, 45^{\circ}, 60^{\circ}, 67.5^{\circ}, 75^{\circ}$, and $90^{\circ}$; then these 12 groups are fitted to 12 function curves using MATLAB, as shown in Figure 5.

The 12 fitted function curve formulas can be expressed as

$$
\begin{aligned}
F_{\mathrm{I} 90^{\circ}}\left(\frac{a}{h}\right)= & 6.318\left(\frac{a}{h}\right)^{4}-4.407\left(\frac{a}{h}\right)^{3} \\
& +3.683\left(\frac{a}{h}\right)^{2}-0.6562\left(\frac{a}{h}\right) \\
& +1.062
\end{aligned}
$$

$$
\begin{aligned}
F_{\mathrm{I} 75^{\circ}}\left(\frac{a}{h}\right)= & -1.368\left(\frac{a}{h}\right)^{4}+5.916\left(\frac{a}{h}\right)^{3} \\
& -1.296\left(\frac{a}{h}\right)^{2}+0.2301\left(\frac{a}{h}\right) \\
& +0.9543
\end{aligned}
$$

$$
\begin{aligned}
F_{\mathrm{I} 67.5^{\circ}}\left(\frac{a}{h}\right)= & -4.167\left(\frac{a}{h}\right)^{4}+8.464\left(\frac{a}{h}\right)^{3} \\
& -2.622\left(\frac{a}{h}\right)^{2}+0.4994\left(\frac{a}{h}\right)
\end{aligned}
$$




$$
\begin{aligned}
& F_{\mathrm{I} 60^{\circ}}\left(\frac{a}{h}\right)=0.5975\left(\frac{a}{h}\right)^{4}+0.387\left(\frac{a}{h}\right)^{3} \\
& +1.023\left(\frac{a}{h}\right)^{2}-0.1228\left(\frac{a}{h}\right) \\
& +0.8348 \\
& F_{\mathrm{I} 45^{\circ}}\left(\frac{a}{h}\right)=-3.497\left(\frac{a}{h}\right)^{4}+6.955\left(\frac{a}{h}\right)^{3} \\
& -3.231\left(\frac{a}{h}\right)^{2}+0.5804\left(\frac{a}{h}\right) \\
& +0.6577 \\
& F_{\mathrm{I} 30^{\circ}}\left(\frac{a}{h}\right)=6.513\left(\frac{a}{h}\right)^{4}-6.949\left(\frac{a}{h}\right)^{3}
\end{aligned}
$$

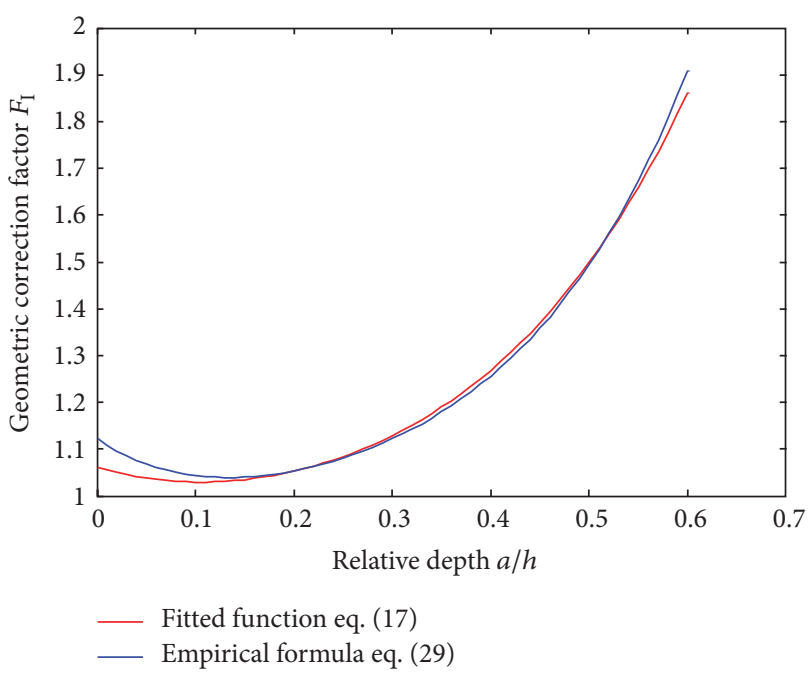$$
+2.75\left(\frac{a}{h}\right)^{2}-0.4081\left(\frac{a}{h}\right)
$$$$
+0.4436
$$$$
F_{\mathrm{II} 90^{\circ}}\left(\frac{a}{h}\right)=0
$$$$
F_{\mathrm{II} 75^{\circ}}\left(\frac{a}{h}\right)=-1.117\left(\frac{a}{h}\right)^{4}+1.696\left(\frac{a}{h}\right)^{3}
$$$$
-0.6814\left(\frac{a}{h}\right)^{2}+0.06768\left(\frac{a}{h}\right)
$$$$
+0.1534
$$$$
\begin{aligned}
F_{\mathrm{II} 67.5^{\circ}}\left(\frac{a}{h}\right)= & 2.125\left(\frac{a}{h}\right)^{4}-2.148\left(\frac{a}{h}\right)^{3} \\
& +0.8833\left(\frac{a}{h}\right)^{2}-0.1847\left(\frac{a}{h}\right)
\end{aligned}
$$$$
+0.2365
$$$$
F_{\mathrm{II} 60^{\circ}}\left(\frac{a}{h}\right)=0.1669\left(\frac{a}{h}\right)^{4}-0.06872\left(\frac{a}{h}\right)^{3}
$$$$
+0.1959\left(\frac{a}{h}\right)^{2}-0.1093\left(\frac{a}{h}\right)
$$$$
+0.2901
$$$$
F_{\mathrm{II} 45^{\circ}}\left(\frac{a}{h}\right)=0.3453\left(\frac{a}{h}\right)^{4}-0.2088\left(\frac{a}{h}\right)^{3}
$$$$
+0.2756\left(\frac{a}{h}\right)^{2}-0.1524\left(\frac{a}{h}\right)
$$$$
+0.3336
$$$$
F_{\mathrm{II} 30^{\circ}}\left(\frac{a}{h}\right)=-3.581\left(\frac{a}{h}\right)^{4}+4.705\left(\frac{a}{h}\right)^{3}
$$$$
-1.944\left(\frac{a}{h}\right)^{2}+0.2885\left(\frac{a}{h}\right)
$$$$
+0.2922
$$

where $\theta=30^{\circ}, 45^{\circ}, 60^{\circ}, 67.5^{\circ}, 75^{\circ}$, and $90^{\circ}$ and $a / h \in[0,0.6]$.
FIGURE 6: Comparison between the fitted function and the empirical formula.

As shown in Figure 5, when the oblique crack angle $\theta$ remains unchanged, the geometric correction factors $F_{\mathrm{I} \theta}(a / h)$ and $F_{\mathrm{II} \theta}(a / h)$ gradually increase as the relative crack depth increases. In addition, the increasing amplitude of the geometric correction factors also gradually increases as the relative crack depth increases. When the relative depth of the crack $a / h$ remains unchanged, the geometric correction factor $F_{\mathrm{I} \theta}(a / h)$ gradually increases as the oblique crack angle $\theta$ increases; and when the angle of the oblique crack $\theta=$ $45^{\circ}$, the geometric correction factor $F_{\mathrm{II} \theta}(a / h)$ reaches the maximum.

When the oblique crack angle $\theta=90^{\circ}$, the oblique crack is transformed into the transverse crack, and the empirical formula of the geometric correction factor is given by [22]:

$$
\begin{aligned}
F_{I}\left(\frac{a}{h}\right)= & 14\left(\frac{a}{h}\right)^{4}-13.08\left(\frac{a}{h}\right)^{3}+7.33\left(\frac{a}{h}\right)^{2} \\
& -1.4\left(\frac{a}{h}\right)+1.122
\end{aligned}
$$

where $a / h \in[0,0.6]$.

A comparison between (17) fitted by MATLAB and (29) from [22] is shown in Figure 6.

As shown in Figure 6, the two curves are very similar for a relative oblique crack depth of $a / h \in[0.1,0.6]$, and the empirical formula Eq. (29) can be replaced by the fitted function Eq. (17). Additional errors exist between the two curves when the relative depth of the oblique crack is $a / h \in[0,0.1]$, with the maximum error reaching $5.35 \%$. The decreasing amplitude of the geometric correction factor is relatively large for the empirical formula Eq. (29), while the fitted function Eq. (17) is more smooth and practical for a relative oblique crack depth $a / h \in[0,0.1]$.

4.2. Natural Frequency of the Breathing Oblique Cracked Beam. ABAQUS is used to build the geometric mesh model of the beam with a breathing oblique crack. The 


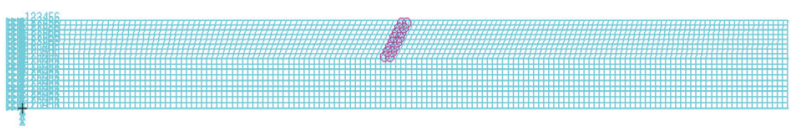

(a) Mesh model of the breathing oblique cracked beam

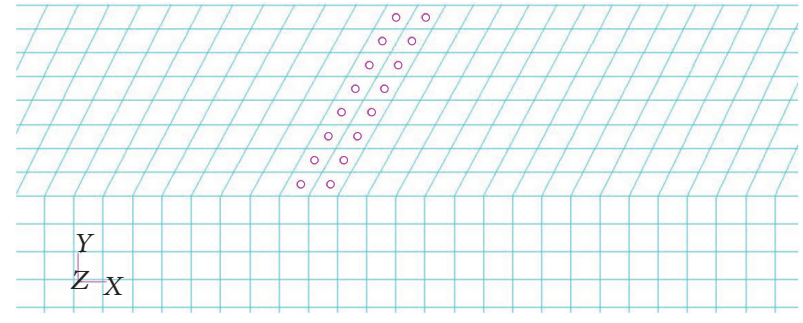

(b) Mesh model of the crack region

FIGURE 7: Mesh model of the breathing oblique crack.

three-dimensional model is then applied to build threedimensional geometric model meshes.

The breathing behaviour of the oblique crack is treated as a full frictional contact problem between the crack surfaces, and penetration between contacting areas is not allowed. A transverse harmonic excitation is acting at the free end of the cantilever beam, and a reasonable frequency range is set up. Set the displacement/velocity/acceleration as the output, then the transverse acceleration magnitude-frequency characteristic curve of the breathing cracked beam can be obtained.

The first-order natural frequency of the breathing cracked beam can be determined from the first peak of the curve and compared with the results from the analytical method proposed in this paper. The cracked beam meshes and contacts on both crack surfaces are shown in Figure 7, where the angle of the oblique crack is $\theta=60^{\circ}$, and the relative depth of the oblique crack is $a / h=0.5$.

\section{Results and Discussion}

Using the cantilever beam as an example, the geometric parameters of the oblique cracked beam in Figure 1 are $L=$ $0.3 \mathrm{~m}, h=0.03 \mathrm{~m}$, and $b=0.03 \mathrm{~m}$. The structural material is the low carbon alloy steel AISI1050, with material parameters: $E=210 \mathrm{GPa}, \nu=0.3$, and $\rho=7860 \mathrm{~kg} / \mathrm{m}^{3}$.

We assume that the position of the oblique crack is $x_{a}=$ $0.5 \mathrm{~L}$, the angle of the oblique crack is $\theta=90^{\circ}$, and the relative depth of the oblique crack is $a / h \in[0,0.5]$. The natural frequencies calculated by the fitted function Eq. (17) and the empirical formula Eq. (29) are shown in Figure 8.

As shown in Figure 8, the natural frequencies calculated by the two methods are nearly identical. Therefore, the fitted function Eq. (17) is correct for the oblique crack angle $\theta=$ $90^{\circ}$. The natural frequency of the breathing oblique cracked beam gradually decreases with increased relative depth of the oblique crack when the angle of the oblique crack is $\theta=90^{\circ}$. In addition, the decreasing amplitude gradually increases as the relative depth of the oblique crack increases.

We assume that the position of the oblique crack is $x_{a}=$ $0.5 \mathrm{~L}$, the angle of the oblique crack is $\theta=90^{\circ}$, and the relative depth of the oblique crack is $a / h=0.5$. When the $3 \mathrm{D}$ mesh sizes of the cracked beam are, respectively, $0.015 \mathrm{~m} \times 0.015 \mathrm{~m} \times 0.015 \mathrm{~m}, 0.0075 \mathrm{~m} \times 0.0075 \mathrm{~m} \times 0.0075 \mathrm{~m}$, $0.005 \mathrm{~m} \times 0.005 \mathrm{~m} \times 0.005 \mathrm{~m}, 0.00375 \mathrm{~m} \times 0.00375 \mathrm{~m} \times$
$0.00375 \mathrm{~m}, 0.003 \mathrm{~m} \times 0.003 \mathrm{~m} \times 0.003 \mathrm{~m}, 0.0025 \mathrm{~m} \times 0.0025 \mathrm{~m} \times$ $0.0025 \mathrm{~m}, 0.0015 \mathrm{~m} \times 0.0015 \mathrm{~m} \times 0.0015 \mathrm{~m}, 0.001 \mathrm{~m} \times 0.001 \mathrm{~m} \times$ $0.0015 \mathrm{~m}$, and $0.001 \mathrm{~m} \times 0.001 \mathrm{~m} \times 0.001 \mathrm{~m}$, the total numbers of elements of the breathing cracked cantilever beam are $80,640,2160,5120,10000,17280,80000,180000,270000$, and then the natural frequencies of the breathing oblique cracked beam obtained by ABAQUS are shown in Figure 9.

As shown in Figure 9, the natural frequency of the breathing oblique cracked beam is gradually converging to an exact value as the total number of elements increases. It can be proved that the natural frequency obtained by ABAQUS is convergent, and it can be used to verify the accuracy of the theoretical method proposed in this paper.

We assume that the position of the oblique crack is $x_{a}=$ $0.5 \mathrm{~L}$ and the angles of the oblique crack are $\theta=30^{\circ}, 45^{\circ}, 60^{\circ}$, $67.5^{\circ}, 75^{\circ}, 90^{\circ}, 105^{\circ}, 112.5^{\circ}, 120^{\circ}, 135^{\circ}$, and $150^{\circ}$. If the relative depth of the oblique crack is $a / h \in[0.025,0.5]$, the natural frequencies of the cracked beam can be calculated using the analytical method proposed in this paper for different oblique crack angles and relative depths. If the relative depth of the oblique crack is $a / h=0.1,0.2,0.3,0.4,0.5$, the natural frequencies of the oblique cracked beam can be obtained using ABAQUS. The natural frequencies of the oblique cracked beam that were obtained using the two methods are shown in Figure 1

As shown in Figure 10, the natural frequencies of the cracked beam calculated using the two presented methods are very similar for a variety of oblique crack angles and relative depths, with the maximum computational error reaching only $2.99 \%$. When the angle of the oblique crack remains unchanged, the natural frequency of the breathing oblique cracked beam gradually decreases as the relative depth of the oblique crack increases. In addition, the decreasing amplitude gradually increases as the relative depth of the oblique crack increases. The decreasing natural frequency rate of the oblique cracked beam gradually increases as the oblique crack angle approaches $90^{\circ}$.

We assume that the position of the oblique crack is $x_{a}=$ $0.5 L$, the relative depth of the crack is $a / h \in[0.05,0.5]$, and the angles of the oblique crack are $\theta \in\left\{30^{\circ} 150^{\circ}\right\}$, $\theta \in\left\{45^{\circ} 135^{\circ}\right\}, \theta \in\left\{60^{\circ} 120^{\circ}\right\}, \theta \in\left\{67.5^{\circ} 112.5^{\circ}\right\}$, and $\theta \in\left\{75^{\circ} 105^{\circ}\right\}$. The natural frequencies of the breathing oblique cracked beam calculated using the proposed analytical method are shown in Figure 11. 


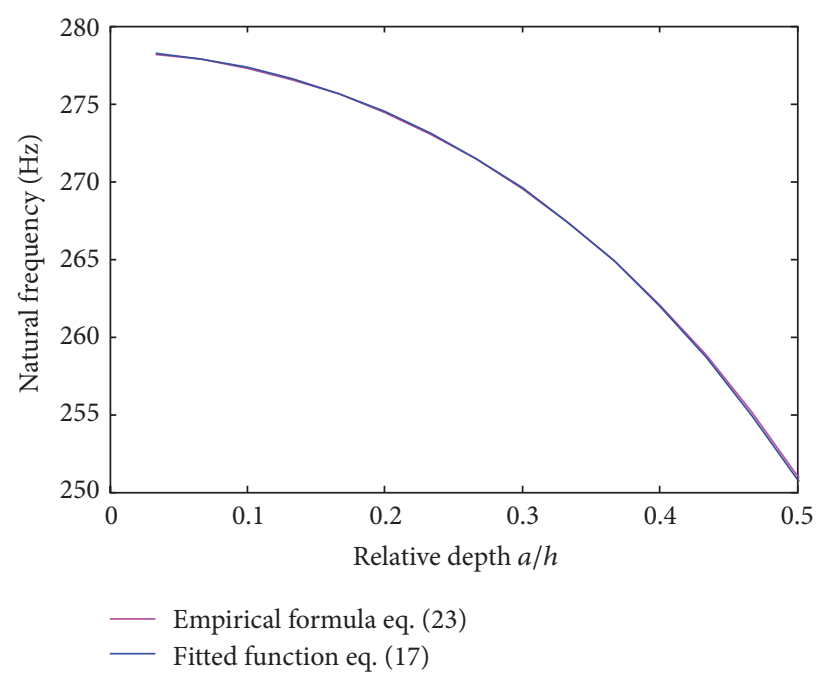

FIgURE 8: Natural frequencies of the fitted function and the empirical formula.

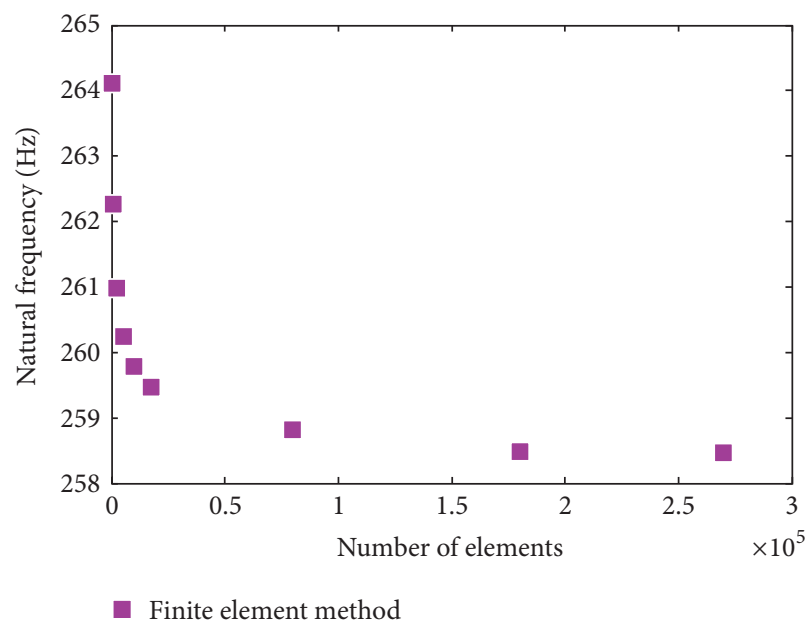

FIGURE 9: Natural frequency obtained by ABAQUS with different number of elements.

As shown in Figure 11, when the angle of the oblique crack is less than $90^{\circ}$, the natural frequencies of the breathing oblique cracked beam are less than natural frequencies for angles greater than $90^{\circ}$. In addition, the influence of the angle on the natural frequency of the cracked beam is relatively large. The decreasing amplitude of the natural frequency gradually increases as the relative depth of the oblique crack increases.

We assume that the position of the oblique crack is $x_{a}=0.5 L$, the relative depth of the oblique crack is $a / h=$ $0.1,0.2,0.3,0.4,0.5$, and the angles of the oblique crack are $\theta=30^{\circ}, 45^{\circ}, 60^{\circ}, 67.5^{\circ}, 75^{\circ}, 90^{\circ}, 105^{\circ}, 112.5^{\circ}, 120^{\circ}, 135^{\circ}$, and $150^{\circ}$. The natural frequencies of the breathing oblique cracked beam calculated using the analytical method proposed are shown in Figure 12.

As shown in Figure 12, the natural frequency of the breathing oblique cracked beam gradually decreases as the relative depth of the crack increases when the oblique crack angle remains unchanged. When the relative depth of the oblique crack remains unchanged and the angle of the crack is $\theta \in\left[30^{\circ}, 90^{\circ}\right]$, the natural frequency of the beam gradually decreases as the angle increases, and the decreasing amplitude gradually decreases as the angle increases. If the relative depth of the oblique crack remains unchanged and the angle of the crack is $\theta \in\left[90^{\circ}, 150^{\circ}\right]$, then the natural frequency of the beam gradually increases as the angle increases, and the increasing amplitude gradually increases as the angle increases. When the relative depth of the oblique crack remains unchanged and the angle of the oblique crack is $\theta=90^{\circ}$, the natural frequency of the beam is minimal, and the influence of the crack on the natural frequency is maximal.

We assume that the position of the oblique crack is $x_{a} / L \epsilon$ $[0.1,0.95]$, the angle of the oblique crack is $\theta=90^{\circ}$, and the 


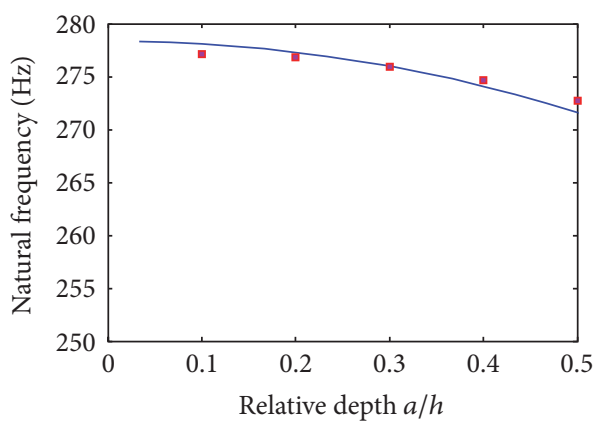

- Breathing crack $30^{\circ}$

- Finite element method $30^{\circ}$

(a) $\theta=30^{\circ}$

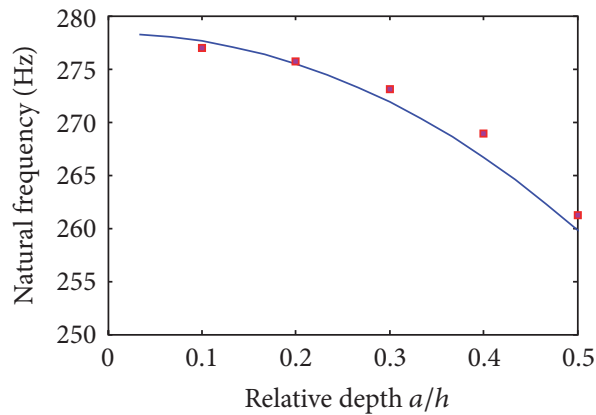

- Breathing crack $60^{\circ}$

- Finite element method $60^{\circ}$

(c) $\theta=60^{\circ}$

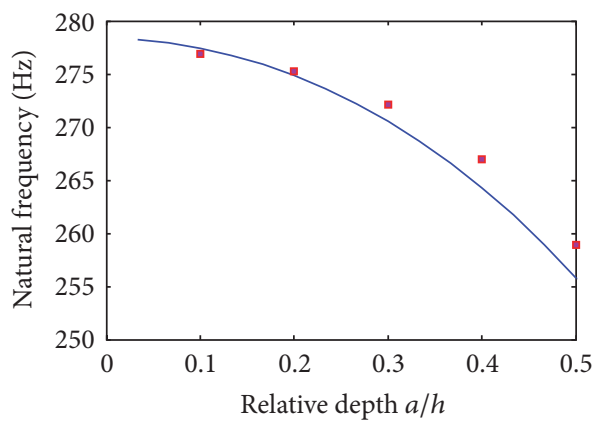

— Breathing crack $75^{\circ}$

- Finite element method $75^{\circ}$

(e) $\theta=75^{\circ}$

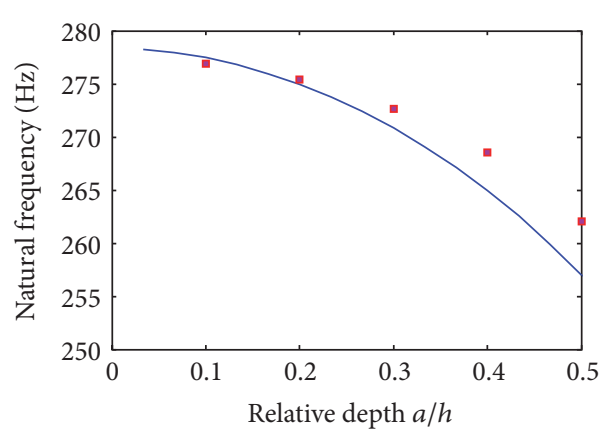

- Breathing crack $105^{\circ}$

- Finite element method $105^{\circ}$

(g) $\theta=105^{\circ}$

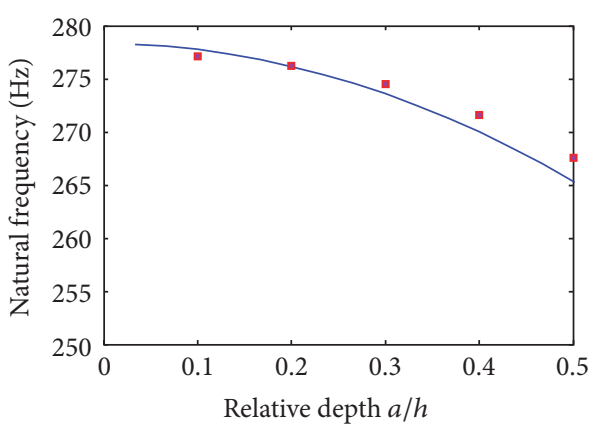

Breathing crack $45^{\circ}$

- Finite element method $45^{\circ}$

(b) $\theta=45^{\circ}$

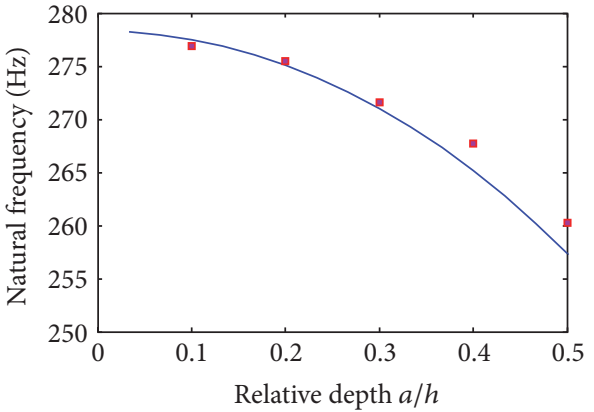

Breathing crack $67.5^{\circ}$

- Finite element method $67.5^{\circ}$

(d) $\theta=67.5^{\circ}$

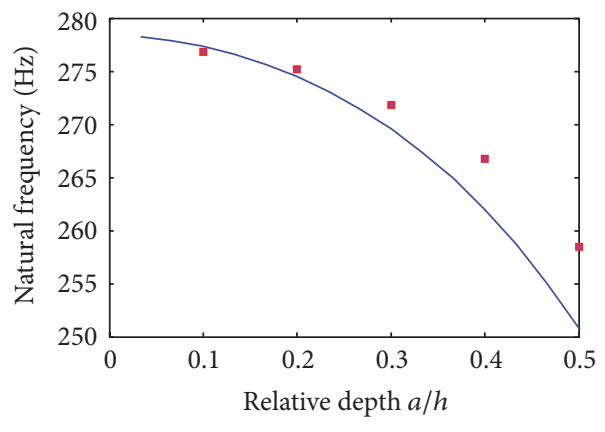

— Breathing crack $90^{\circ}$

- Finite element method $90^{\circ}$

(f) $\theta=90^{\circ}$

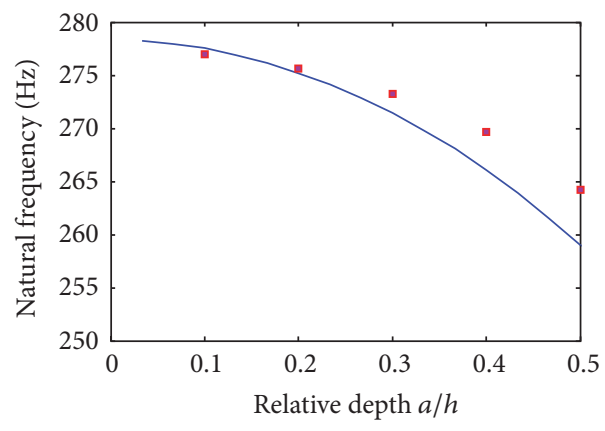

Breathing crack $112.5^{\circ}$

- Finite element method $112.5^{\circ}$

(h) $\theta=112.5^{\circ}$

Figure 10: Continued. 


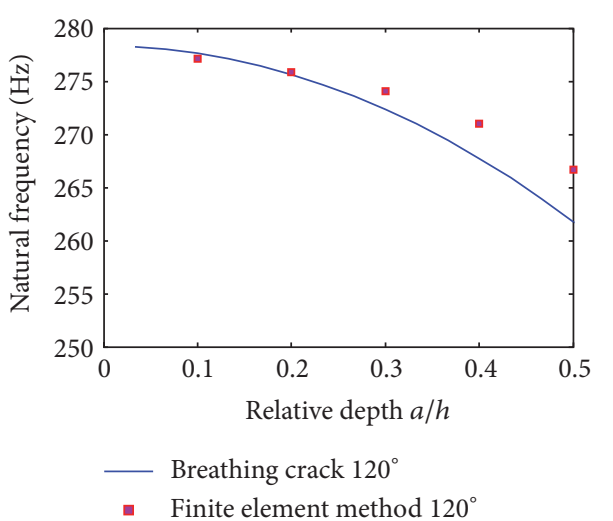

(i) $\theta=120^{\circ}$

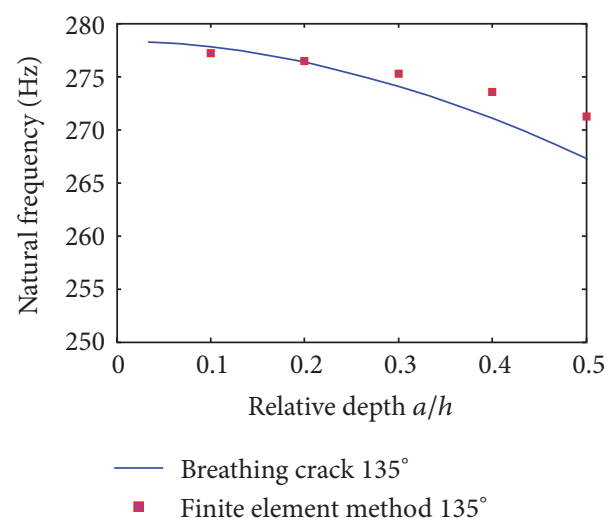

(j) $\theta=135^{\circ}$

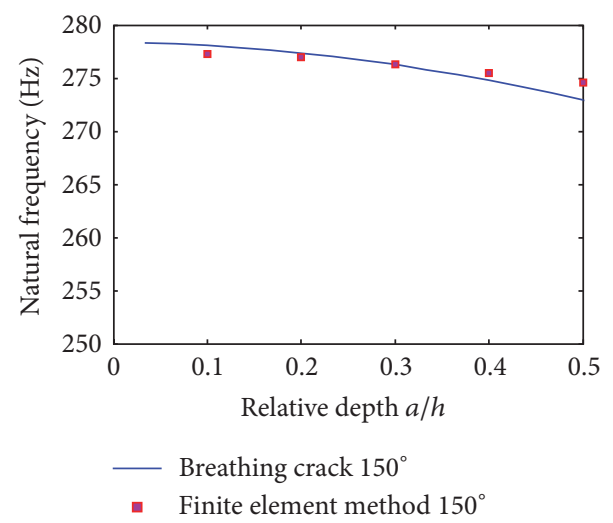

(k) $\theta=150^{\circ}$

FIGURE 10: Natural frequencies obtained using the theoretical method and the ABAQUS FEM method.

relative depth of the oblique crack is $a / h=0.5$. The natural frequencies of the breathing oblique cracked beam calculated using the proposed analytical method and ABAQUS are shown in Figure 13.

As shown in Figure 13, the natural frequencies of the cracked beam calculated using the two methods are very close, for a variety of oblique crack relative positions, with the maximum computational error reaching only $4.65 \%$. The position of the oblique crack has a significant influence on the natural frequency of the breathing oblique cracked beam. When the angle and relative depth of the oblique crack remain unchanged, the natural frequency of the cracked beam gradually increases as the crack moves away from the fixed end of the cantilever beam. The increasing amplitude of the natural frequency gradually decreases as the relative position of the oblique crack from the fixed end of the cantilever beam increases.

\section{Conclusion}

An analytical method for evaluating the natural frequency of the cantilever beam with a breathing oblique crack has been developed. The method proposes a new model for simulating the breathing behaviour of the oblique crack, which is represented by the double-linear-springs-model. The proposed method also involves the calculation of geometric correction factors for the oblique crack with different angles and relative depths. These geometric correction factors are used to calculate the stress intensity factors at the crack tip. The Galerkin method is used to simplify the structure to a single degree of freedom system, allowing the natural frequency of the cracked beam to be obtained.

The proposed analytical method was validated using the ABAQUS FEM software, which is used to build geometric and mesh models of the oblique cracked beam. The natural frequencies of the oblique cracked beam obtained via the two methods are extremely similar, with a maximum computational error of only $4.65 \%$.

The analytical method proposed in this paper provides a powerful tool for calculating the natural frequency of the beam with a breathing oblique crack. This method can be applied to beams with multiple breathing oblique cracks, and several double-linear-springs-models can be used to simulate the breathing behaviours of each oblique crack. 


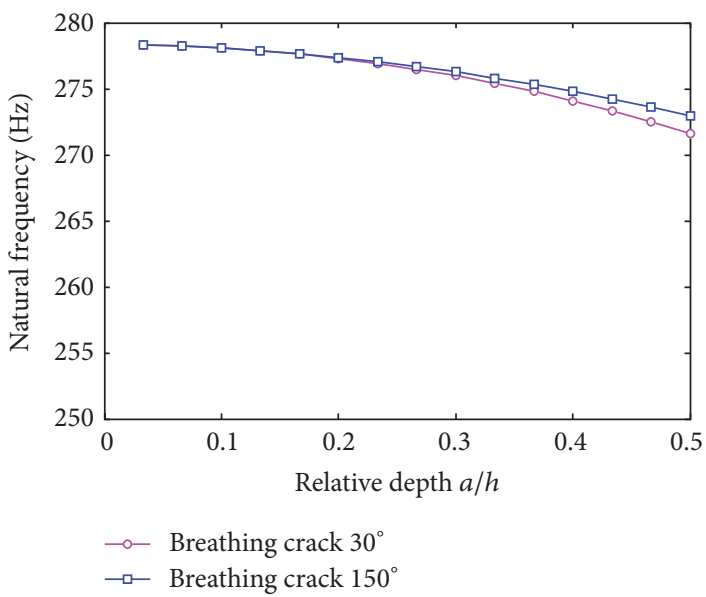

(a) $\theta \in\left\{\begin{array}{ll}30^{\circ} & 150^{\circ}\end{array}\right\}$

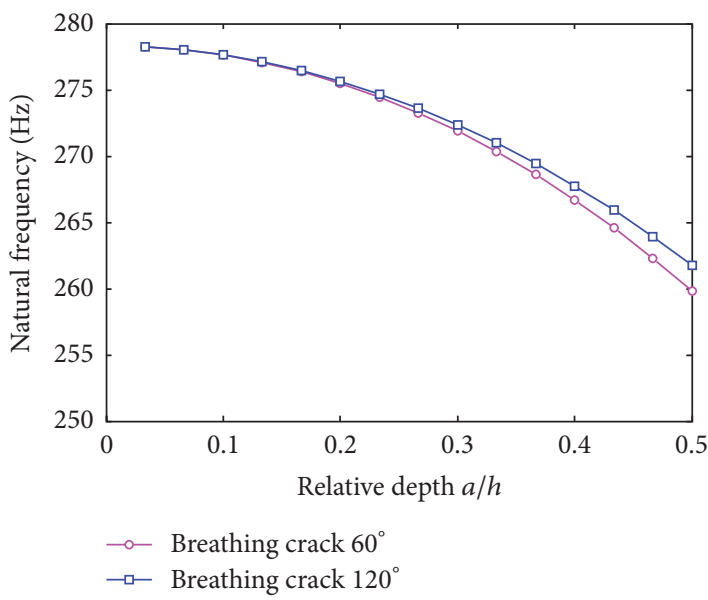

(c) $\theta \in \begin{cases}60^{\circ} & \left.120^{\circ}\right\}\end{cases}$

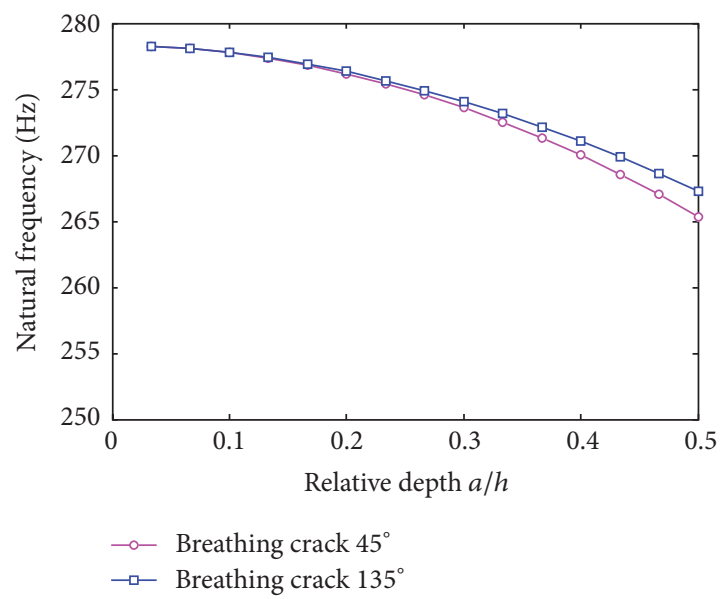

(b) $\theta \in\left\{\begin{array}{ll}45^{\circ} & 135^{\circ}\end{array}\right\}$

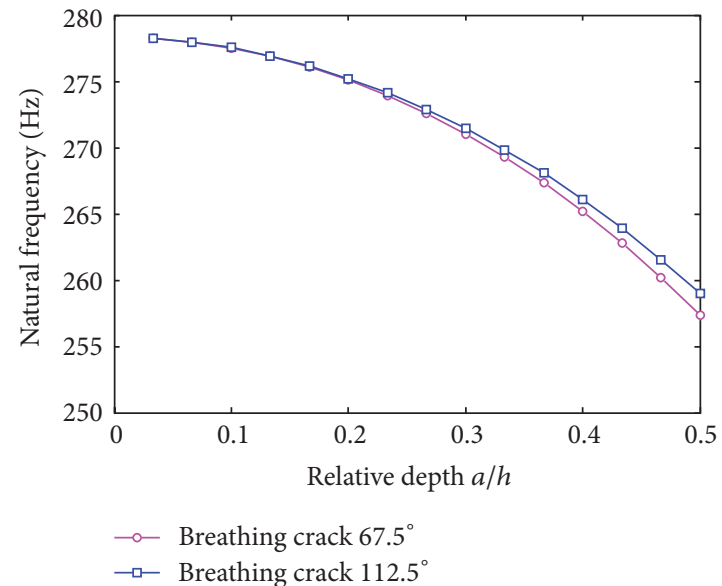

(d) $\theta \in\left\{\begin{array}{ll}67.5^{\circ} & 112.5^{\circ}\end{array}\right\}$

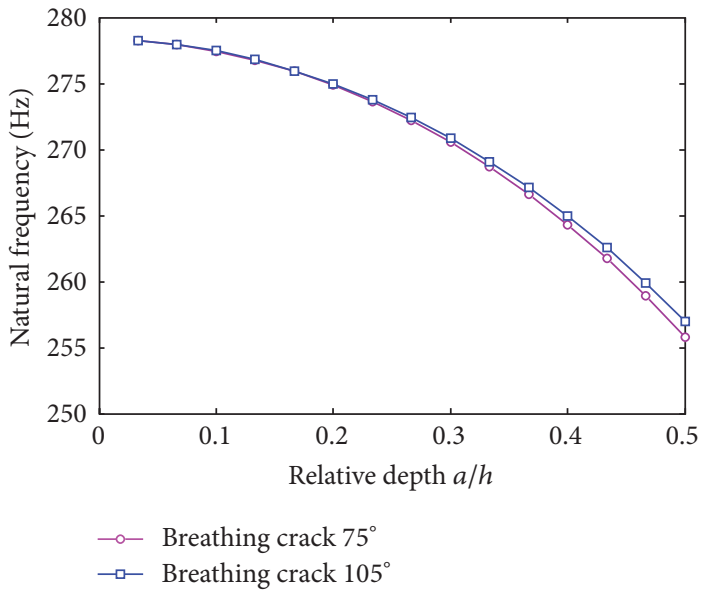

(e) $\theta \in \begin{cases}75^{\circ} & \left.105^{\circ}\right\}\end{cases}$

FIGURE 11: Comparison between the natural frequencies of the oblique crack with different angles.

The modal analysis of the cantilever beam with a breathing oblique crack is carried out in this paper, and the possibility is provided for developing the structural health monitoring system of the beam with an oblique crack.
Finally, six additional function curves have been fitted for oblique crack angles of $\theta=30^{\circ}, 60^{\circ}$, and $75^{\circ}$, enriching the data provided in [19] for a unilateral oblique crack subjected to a bending moment. 


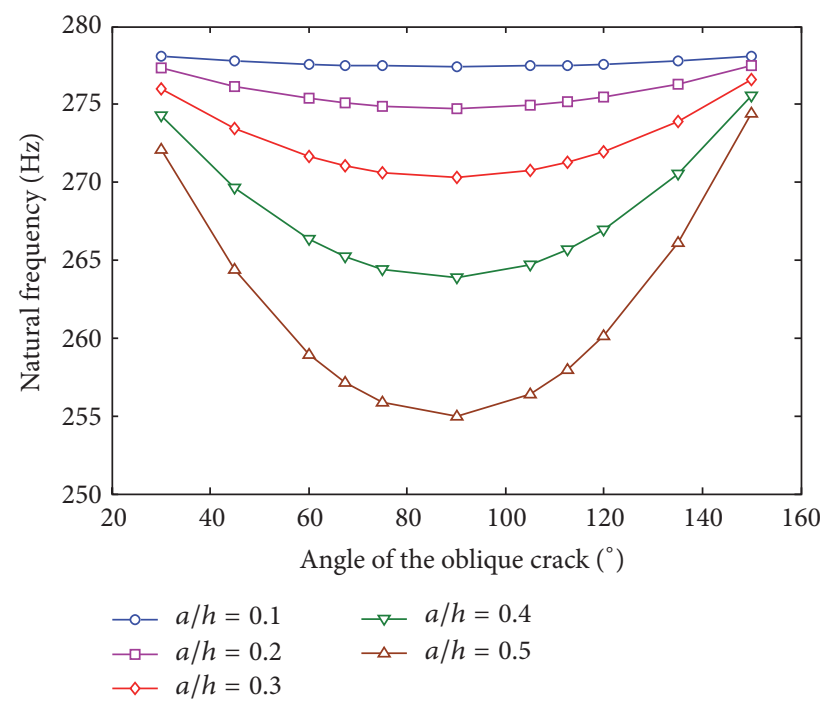

FIGURE 12: Natural frequencies of the breathing oblique crack with different relative depths.

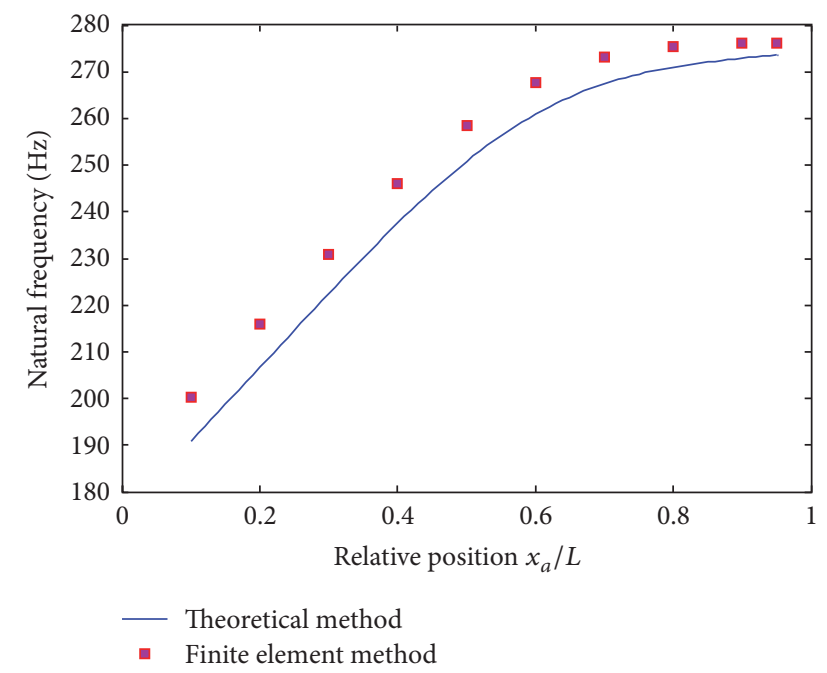

FIGURE 13: Natural frequencies of the oblique crack for different positions.

\section{Competing Interests}

The authors declare that they have no competing interests.

\section{Acknowledgments}

This study was conducted as part of a project funded by the Priority Academic Program Development of Jiangsu Higher Education Institutions (PAPD).

\section{References}

[1] C. A. Papadopoulos and A. D. Dimarogonas, "Coupled longitudinal and bending vibrations of a cracked shaft," Journal of
Vibration, Acoustics, Stress, and Reliability in Design, vol. 110, no. 1, pp. 1-8, 1988.

[2] T. G. Chondros, A. D. Dimarogonas, and J. Yao, "A continuous cracked beam vibration theory," Journal of Sound and Vibration, vol. 215, no. 1, pp. 17-34, 1998.

[3] T. G. Chondros, A. D. Dimarogonas, and J. Yao, "Vibration of a beam with a breathing crack," Journal of Sound and Vibration, vol. 239, no. 1, pp. 57-67, 2001.

[4] O. N. L. Abraham and J. A. Brandon, "The modelling of the opening and closure of a crack," Journal of Vibration \& Acoustics, vol. 117, no. 3, pp. 370-377, 1995.

[5] S. M. Cheng, A. S. J. Swamidas, X. J. Wu, and W. Wallace, "Vibrational response of a beam with a breathing crack," Journal of Sound \& Vibration, vol. 225, no. 1, pp. 201-208, 1999.

[6] N. Wu, "Study of forced vibration response of a beam with a breathing crack using iteration method," Journal of Mechanical Science and Technology, vol. 29, no. 7, pp. 2827-2835, 2015.

[7] N. Hasebe, J. Qian, and Y. Chen, "Fundamental solutions for half plane with an oblique edge crack," Engineering Analysis with Boundary Elements, vol. 17, no. 4, pp. 263-267, 1996.

[8] D. B. Rayaprolu and D. P. Rooke, "Influence functions for inclined edge cracks," Fatigue and Fracture of Engineering Materials \& Structures, vol. 21, no. 6, pp. 761-769, 1998.

[9] M. Beghini, L. Bertini, and V. Fontanari, "Stress intensity factors for an inclined edge crack in a semiplane," Engineering Fracture Mechanics, vol. 62, no. 6, pp. 607-613, 1999.

[10] H. K. Kim and S. B. Lee, "Stress intensity factors of an oblique edge crack subjected to normal and shear tractions," Theoretical and Applied Fracture Mechanics, vol. 25, no. 2, pp. 147-154, 1996.

[11] M. Beghini, M. Benedetti, V. Fontanari, and B. D. Monelli, "A general weight function for inclined kinked edge cracks in a semi-plane," Engineering Fracture Mechanics, vol. 77, no. 11, pp. 1631-1643, 2010.

[12] M. Beghini, M. Benedetti, V. Fontanari, and B. D. Monelli, "Stress intensity factors of inclined kinked edge cracks: a simplified approach," Engineering Fracture Mechanics, vol. 81, pp. 120-129, 2012.

[13] M. Beghini and C. Santus, "An application of the weight function technique to inclined surface cracks under rolling contact fatigue, assessment and parametric analysis," Engineering Fracture Mechanics, vol. 98, no. 1, pp. 153-168, 2013.

[14] M. Beghini, L. Bertini, R. Di Lello, and V. Fontanari, "A general weight function for inclined cracks at sharp V-notches," Engineering Fracture Mechanics, vol. 74, no. 4, pp. 602-611, 2007.

[15] A. Y. T. Leung and R. K. L. Su, "Mixed-mode two-dimensional crack problem by fractal two level finite element method," Engineering Fracture Mechanics, vol. 51, no. 6, pp. 889-895, 1995.

[16] M. J. Jweeg, A. S. Hammood, and M. Al-Waily, "Analytical solution to oblique crack effect for difference composite material plates," Journal of Science and Technology, vol. 2, no. 8, pp. 697716, 2012.

[17] M. Al-Waily, "A suggested analytical solution of oblique crack effect on the beam vibration," International Journal of Energy and Environment, vol. 6, no. 3, pp. 227-246, 2015.

[18] A. D. Dimarogonas, S. A. Paipetis, and T. G. Chondros, Analytical methods in rotor dynamics, vol. 9 of Mechanisms and Machine Science, Springer, Netherlands, Second edition, 2013.

[19] D. P. Rooke and D. J. Cartwright, Compendium of Stress Intensity Factors, Her Majesty's Stationery Office, London, UK, 1976.

[20] W. Liu and G. Chen, "Coupling analysis of vibration fatigue crack growth for breathing cracked beam," China Mechanical Engineering, vol. 21, no. 23, pp. 2798-2802, 2010. 
[21] E. Douka and L. J. Hadjileontiadis, "Time-frequency analysis of the free vibration response of a beam with a breathing crack," NDT \& E International, vol. 38, no. 1, pp. 3-10, 2005.

[22] H. Tada, The Stress Analysis of Cracks Handbook, Del Research, 1973. 


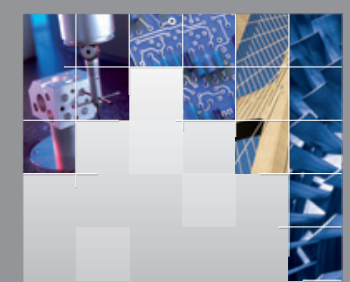

\section{Enfincering}
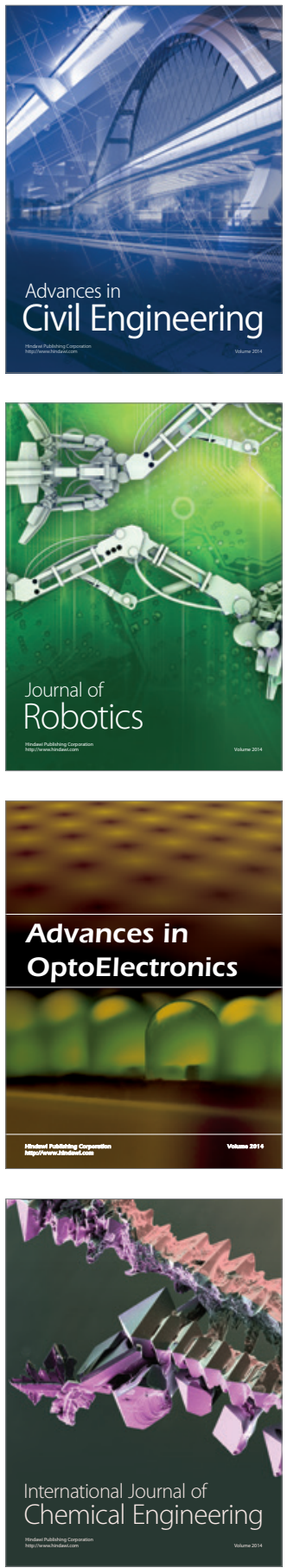

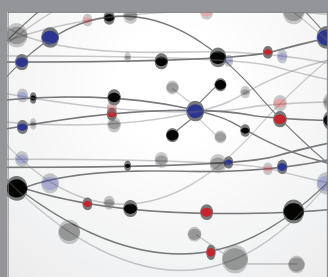

The Scientific World Journal

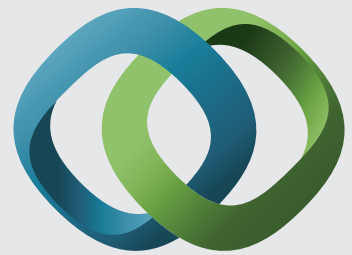

\section{Hindawi}

Submit your manuscripts at

https://www.hindawi.com
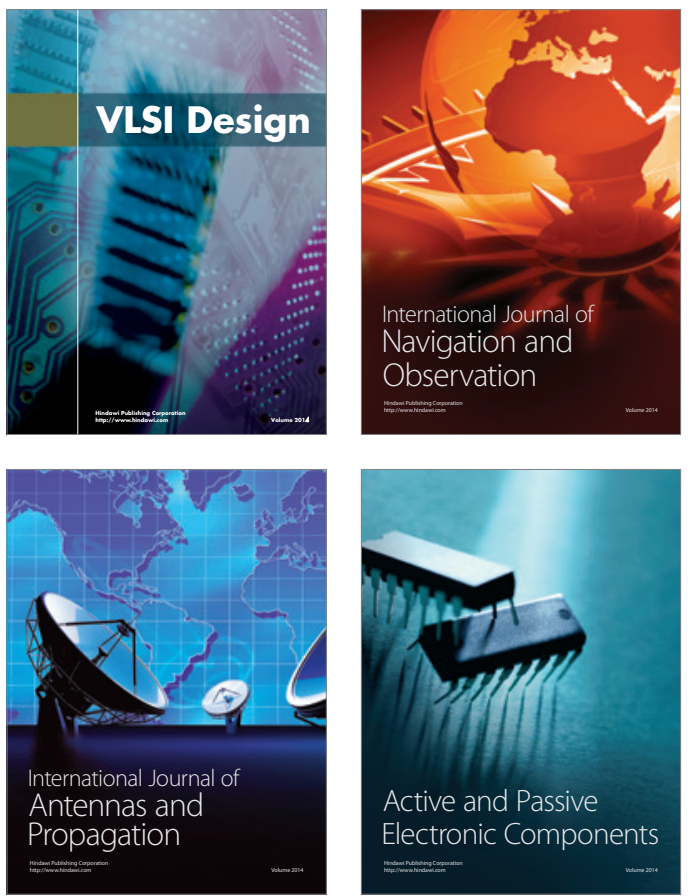
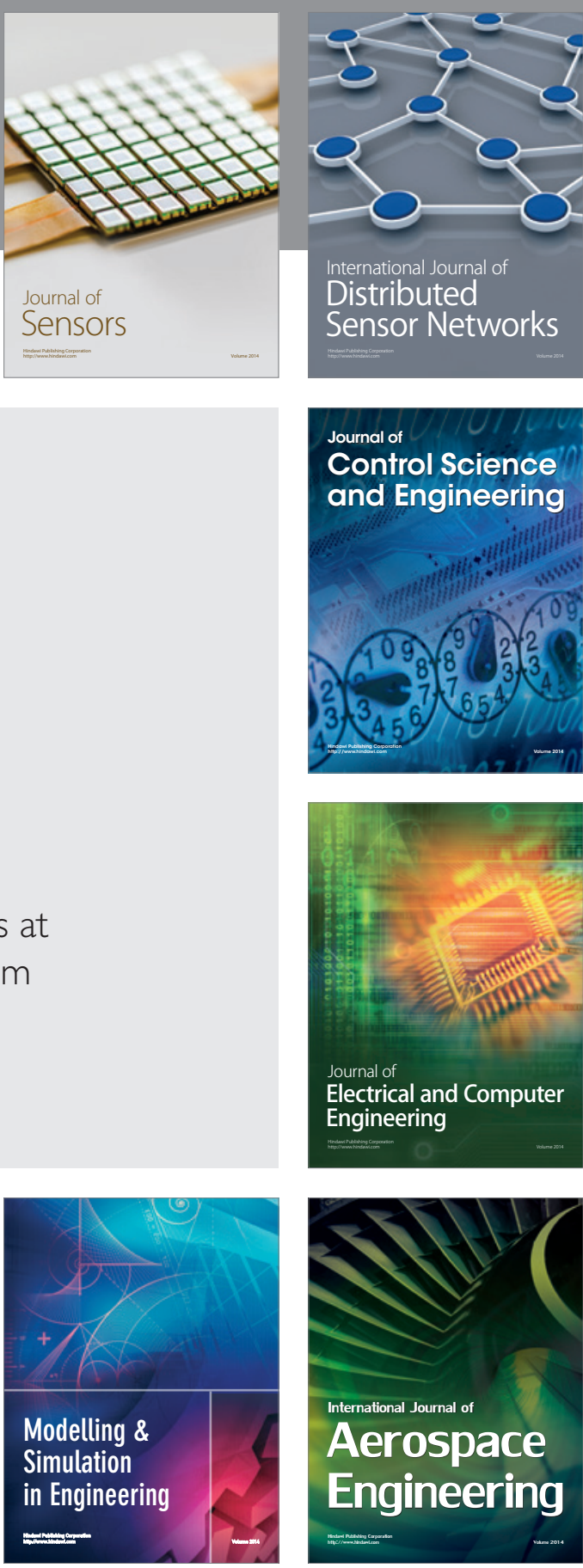

International Journal of

Distributed

Sensor Networks

$-$

Joumal of

Control Science

and Engineering
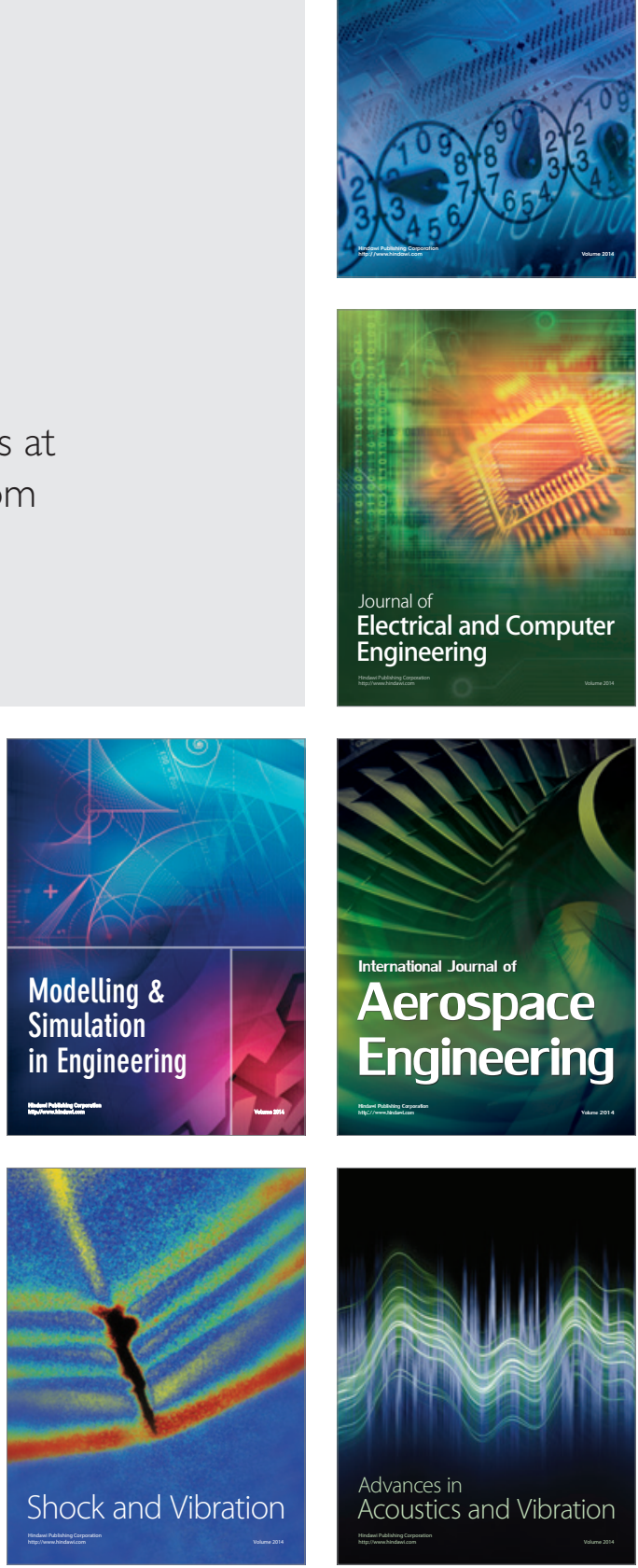